\title{
Revisiting Huey: On the importance of the upper part of words during reading
}

\author{
Manuel Perea
}

Published online: 16 August 2012

(C) Psychonomic Society, Inc. 2012

\begin{abstract}
Recent research has shown that that the upper part of words enjoys an advantage over the lower part of words in the recognition of isolated words. The goal of the present article was to examine how removing the upper/lower part of the words influences eye movement control during silent normal reading. The participants' eye movements were monitored when reading intact sentences and when reading sentences in which the upper or the lower portion of the text was deleted. Results showed a greater reading cost (longer fixations) when the upper part of the text was removed than when the lower part of the text was removed (i.e., it influenced when to move the eyes). However, there was little influence on the initial landing position on a target word (i.e., on the decision as to where to move the eyes). In addition, lexical-processing difficulty (as inferred from the magnitude of the word frequency effect on a target word) was affected by text degradation. The implications of these findings for models of visual-word recognition and reading are discussed.
\end{abstract}

Keywords Visual-word recognition · Reading ·

Eye movements

The vast majority of experiments on normal silent reading have involved sentences in which all words were presented in a pristine condition (see Rayner, Pollatsek, Ashby, \& Clifton, 2012, for a review). Nonetheless, the pattern of eye movements when texts are read under suboptimal

\footnotetext{
M. Perea $(\square)$

ERI-Lectura \& Departamento de Metodología,

Universitat de València,

Av. Blasco Ibáñez, 21,

46010 Valencia, Spain

e-mail: mperea@uv.es
}

circumstances has provided relevant insights into eye movement control (e.g., text with jumbled letters, Rayner, White, Johnson, \& Liversedge, 2006; text with no spaces between words, Pollatsek \& Rayner, 1982; text with disappearing words, Rayner, Liversedge, White, \& Vergilino-Perez, 2003; text with low-contrast words, White \& Staub, 2012). For instance, removing the spaces between words in IndoEuropean languages produces a disruption in the decision of when to move the eyes (i.e., longer fixation durations) and in the decision of where to more the eyes (i.e., initial fixations on the target word are closer to the beginning of the word than to the preferred viewing position; see Rayner, Fischer, \& Pollatsek, 1998).

The present article focuses on yet another suboptimal reading scenario: the study of eye movements when text in which the upper/lower part has been removed is read (see Table 1, for illustration). The interest in this question goes back to Huey (1908), who, in his classic book The Psychology and Pedagogy of Reading, indicated that "the upper part of a letter or word is obviously more important for perception than is the lower half" (p. 65). Huey argued that "we habitually find most meanings in the upper part of objects" and cited Javal as claiming that the eye's fixations tended to move "along between the middle and top of small letters" (p. 65). Huey did not provide any data, and no published studies have experimentally tested Huey's observation during normal reading. There are, however, recent books on speed reading that assert that "scientific studies demonstrate that your retina processes information up to 60 percent faster when you scan only the upper halves of words. Surely in this case, less is more" (Wechsler \& Bell, 2005, p. 62). No citations were provided, though.

If there is a genuine advantage for the upper portion of letters (i.e., more distinctive information at the level of letter features) in the Roman alphabet, this advantage should 
Table 1 Illustration of the conditions in the experiment

\begin{tabular}{|c|c|}
\hline Type of text & Example \\
\hline Intact & The girl asked for a computer at her birthday party \\
\hline Upper part only & The girl acled for a comnutar at har hirthd av narty \\
\hline Lower part only & Ine gill askeu lol a computel al lle vintlluay palty \\
\hline
\end{tabular}

occur with isolated letters. However, Fiset et al. (2009; Fiset et al., 2008) failed to find any bias in favor of the upper portion of isolated lowercase and uppercase letters with the Bubbles technique - an image classification task. ${ }^{1}$ Likewise, Morin-Duchesne, Fiset, Arguin, and Gosselin (2012) replicated this effect with isolated letters in a perceptual identification task, using a parametrical manipulation of top-down and bottom-up masks. The lack of a bias for the upper part of letters is consistent with computational models of visual-word recognition (e.g., McClelland \& Rumelhart, 1981; see also Davis, 2010; Paap, Newsome, McDonald, \& Schvaneveldt, 1982), because these models do not assign any special role to the upper portion of letters. Nonetheless, the advantage of the upper part of letters does occur during the recognition of individual words, as three recent studies have revealed. First, using the Bubbles technique, Blais et al. (2009) found that the participants obtained more information from the upper part of the letters in words than from the lower part-unlike isolated letters with the same technique (see also Morin-Duchesne et al., 2012, for a similar dissociation for isolated letters vs. words when top-down and bottom-up masks were used). Second, Perea, Comesaña, Soares, and Moret-Tatay (2012) found that the magnitude of masked identity priming was greater when the primes preserved the upper part than when the primes preserved the lower part (e.g., metrn-METRO vs. hntel-METRO [around $43 \mathrm{~ms}$ ] greater than MEᄂ_u-METRO vs.

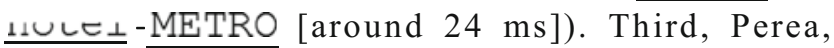
Comesaña, and Soares (in press) found an advantage for the upper part of words when the upper/lower portion of the words was briefly $(50 \mathrm{~ms})$ delayed (i.e., shorter response times to ronoral-general than to yentera-general); importantly, the advantage for the upper part of letters of words was absent for pseudowords. Taken together, these findings suggest that "the bias for the upper part of words comes from the interaction of letter representations and lexical representations" (Perea et al., in press).

The goal of the present experiment was to examine eye movement behavior during a sentence-reading task in which the upper or lower portion of the text was removed (see Table 1). For comparison purposes, intact text was

\footnotetext{
${ }^{1}$ The Bubbles technique uses Gaussian blobs (i.e., bubbles) so that the stimulus parts that are visible vary through time and occur in different locations (see Fiset et al., 2009, Fig. 1, for illustration).
}

employed as a baseline. Thus, the experiment may provide relevant information concerning the locus of the advantage for the upper part of the words, using an ecologically valid procedure (normal reading), and also test Huey's (1908) intuition. Of particular interest is to examine how the deletion of the upper/lower portion of the words affects when to look next (i.e., fixation durations) and where to look next (i.e., eye movement guidance; e.g., the initial landing position on a target word), relative to the baseline intact condition (for computational models of eye movement control, see Engbert, Nuthmann, Richter, \& Kliegl, 2005; Reichle, Pollatsek, Fisher, \& Rayner, 1998). All sentences included a target word that could be either a high- or a low-frequency word (Rayner et al., 2006; see also Paterson \& Jordan, 2010; Perea \& Acha, 2009; White, Johnson, Liversedge, \& Rayner, 2008, among others). The rationale of including word frequency as a factor was to examine whether text degradation (via the removal of the upper/lower part of the words) would affect lexical processing difficulty (e.g., Perea \& Rosa, 2002). For the local measures on the target word, gaze durations (i.e., the sum of the fixation durations on a given word before leaving it) are typically considered the most appropriate index of "initial encoding time for a word" (Rayner et al., 2012) (note that, gaze durations may reflect some (higher-level) lexical/semantic processing, as compared with first-fixation durations). In sum, if the advantage for the upper part of words has a lexical nature (as was suggested above), the effect of word frequency should be magnified (for gaze durations) when the upper part of the word is removed.

\section{Method}

\section{Participants}

Twenty-four undergraduate students from the University of Valencia participated in the experiment in exchange for a small monetary compensation $(3 €)$. All of them were native speakers of Spanish, had normal or corrected-to-normal vision, and were naive about the experimental conditions.

\section{Apparatus}

The eyetracker was an Eyelink II (SR Research Ltd, Canada). This is a video-based eye-tracking device with cameras that sample pupil location at a rate of $500 \mathrm{~Hz}$. The average gaze position error is less than $0.5^{\circ}$. Only the movements of the right eye were monitored. Participants were seated $70 \mathrm{~cm}$ from the screen. A headtracking camera served to compensate for potential head motion. 


\section{Materials}

The sentences were taken from the Perea and Acha (2009) experiment. The target words were the 60 low-frequency words (mean frequency, 4.5 per million [range: $0.18-20$ ]; number of letters, 7.3 [range: 6-9]; Davis \& Perea, 2005) and 60 high-frequency words (mean frequency, 87.3 per million [range: 22-353]; number of letters, 7.3 [range: 6$9]$ ), which were embedded in sentences. To increase experimental power when the word frequency effect was tested, two sentence frames were created for each high-/low-frequency word pair, as in "Marco ha trabajado como joyero/ médico durante toda su vida" (set 1) and "Mi madre preguntó al joyero/médico si aquel diploma era original" (set 2) ("joyero" [jeweler] is a low-frequency word, and "doctor" [doctor/physician] is a high-frequency word). This way, all participants were presented with the 120 target words. The target words embedded in the sentences had a low predictability, and all the sentences were easy to read/understand (for further details, see Perea \& Acha, 2009). For each set of materials, three lists of materials were created so that each participant received 40 intact sentences, 40 sentences in which the lower part of text was removed, and 40 sentences in which the upper part of the text was removed. The criterion for distinguishing the upper from the lower part of the words was simply defined in terms of $y$-coordinates. Specifically, the criterion was the horizontal line in the lowercase letter "e." This horizontal line marked the limit both for the text in which the upper part was deleted and for the text in which the lower part was deleted; this line was preserved in the two degraded conditions. ${ }^{2}$ The sentences were counterbalanced across the three conditions in the two sets of materials.

\section{Statistical analyses}

Global measures (total reading time, average [progressive/ regressive] fixation durations, and number of [progressive/ regressive] fixations) were examined for the three types of text. In addition, local measures on the target word were also analyzed: first-fixation duration (i.e., the duration of the initial fixation on the target word), gaze duration (i.e., the sum of the durations of all fixations on the target word before leaving it), total time (i.e., the sum of all fixation

\footnotetext{
2 The same criterion as that used to define the upper/lower part of the words was employed by Perea et al. (in press; Perea et al., 2012). Although this criterion may not reflect the exact midway in terms of $y$ coordinates, pilot testing revealed that participants had difficulty when reading sentences with a more extreme manipulation of the $y$-coordinates. Note that Perea et al. (2012) employed two degrees of degradation for the upper part of the masked words: metro versus metro (the red area was deleted), and the priming effects were similar regardless of the degree of degradation.
}

durations on the target word, including progressive/regressive saccades), and the position of the initial fixation. The statistical analyses (at both the global and local levels) were conducted by participants and items.

\section{Procedure}

The experiment took place in a silent, dimly lit room. Participants were seated in front of a computer screen and were told that, on each trial, a sentence would appear on the computer screen. Participants were instructed to read each sentence silently for comprehension. Each trial started with a black square on the left-hand side of the monitor. Once the participant looked at that square, the sentence appeared on a single line of text; the location of the square corresponded to that of the initial letter of the sentence. Participants were asked to press a key on a game pad when they had finished reading the sentence; this triggered the next trial. Before starting the experiment, the eyetracker was calibrated, and the participant was asked to follow some dots on the computer screen. Sentences were presented in 14-point Times New Roman font using Eyetrack software (www. psych.umass.edu/eyelab/software/). The 120 experimental sentences were preceded by 9 practice sentences $(3$ sentences of each type) to familiarize the participants with the procedure. The calibration of the eyetracker was checked before the presentation of each sentence, and the eyetracker was recalibrated when necessary. Sentences were presented in a different random order for each participant. Participants were told that the sentences could have their upper/lower part deleted and that (when in doubt) they had to guess the whole word on the basis of the remaining parts. To make sure that the participants were reading for comprehension, they were told that they were going to be asked comprehension questions after the experiments. After the experiment, participants were asked to fill in a list of 15 incomplete sentences ( 5 for each type of text) that were presented in the experiment; one of the missing words in each sentence was always the target word.

\section{Results}

Fixations shorter than $80 \mathrm{~ms}$ that were within one letter of the next/previous fixation were combined into that fixation. Once this procedure was completed, and to avoid the influence of extreme data, fixations shorter than $80 \mathrm{~ms}$ or longer than $800 \mathrm{~ms}$ were excluded (3.51\% of trials). The averages from the global and local analyses are displayed in Tables 2 and 3, respectively. The accuracy score in the postexperiment questionnaire was $4.38(S D=0.15)$ (out of 5) for the intact sentences, while it was $4.04(S D=0.19)$ for the sentences in which only the upper part was preserved and $3.83(S D=0.18)$ for the sentences in which only the lower part was preserved; pairwise comparison revealed that the 
Table 2 Global measures for each of the conditions (means and standard errors): Total sentence reading time (in milliseconds), forward/backward fixation duration (in milliseconds), and number of forward/backward saccades

\begin{tabular}{|c|c|c|c|c|c|c|c|c|c|c|}
\hline & \multirow{2}{*}{\multicolumn{2}{|c|}{ Total reading time }} & \multicolumn{4}{|c|}{ Mean fixation duration } & \multicolumn{4}{|c|}{ Number of saccades } \\
\hline & & & \multicolumn{2}{|c|}{ Progressive } & \multicolumn{2}{|c|}{ Regressive } & \multicolumn{2}{|c|}{ Progressive } & \multicolumn{2}{|c|}{ Regressive } \\
\hline & $M$ & $S E$ & $M$ & $S E$ & $M$ & $S E$ & $M$ & $S E$ & $M$ & $S E$ \\
\hline \multicolumn{11}{|l|}{ Type of text } \\
\hline Intact & 2,251 & 119.3 & 233 & 5.0 & 213 & 5.4 & 8.0 & 0.31 & 2.2 & 0.17 \\
\hline Upper part only & 2,539 & 114.2 & 243 & 4.2 & 230 & 5.8 & 8.6 & 0.31 & 2.3 & 0.17 \\
\hline Lower part only & 4,043 & 172.9 & 273 & 4.4 & 280 & 5.6 & 11.0 & 0.40 & 3.8 & 0.25 \\
\hline
\end{tabular}

only significant difference was between the latter condition and the intact condition $(p=.009)$. Thus, even though there was some difficulty associated with the text in which only the lower part was preserved, participants could read this text with a reasonable level of comprehension.

\section{Global analyses}

All five global measures showed a substantial effect of type of text [total time, $F_{1}(2,46)=137.37, M S E=161,874, p<.001$, and $F_{2}(2,238)=458.1, M S E=247,280, p<.001$; average (forward) fixation duration, $F_{1}(2,46)=147.5, M S E=70.6, p<$ .001 , and $F_{2}(2,238)=167.0, M S E=319.4, p<.001$; average (backward) fixation duration, $F_{1}(2,46)=71.18, M S E=405.6$, $p<.001$, and $F_{2}(2,238)=145.72, M S E=1,011.7, p<.001$; number of forward saccades, $F_{1}(2,46)=88.81, M S E=0.648$, $p<.001$, and $F_{2}(2,238)=385.6, M S E=0.774, p<.001$; number of backward saccades, $F_{1}(2,46)=55.73, M S E=0.35$, $p<.001$, and $\left.F_{2}(2,238)=124.1, M S E=0.788, p<.001\right]$. As can be seen in Table 2, there were unambiguous differences on all measures between the upper part only and lower part only conditions favoring the former condition (all $p \mathrm{~s}<.001$ ). The intact condition, however, was significantly different from both degraded conditions on all measures, except that the difference in the number of regressive fixations between the intact text and the text that preserved the upper part was not significant in the analysis by participants, $t_{1}(23)=-1.28, p=.23 ; t_{2}(119)=$ $3.42, p<.002$.

Local analyses

The ANOVA on the first-fixation durations revealed that participants had shorter fixations on high-frequency words than on low-frequency words ( 243 vs. $264 \mathrm{~ms}$, respectively), $F_{1}(1,23)=58.31, M S E=291.1, p<.001 ; F_{2}(1,118)=$ $26.51, M S E=1,657.1, p<.001$. Furthermore, the effect of type of text was also significant, $F_{1}(2,46)=54.88, M S E=$ $771.9, p<.001 ; F_{2}(2,236)=76.67, M S E=1,400.7, p<.001$ : First-fixation durations were shorter for the intact words than for the words in which only the upper part was preserved ( 228 vs. $248 \mathrm{~ms}$, respectively; $p$ s <.001), and in turn, firstfixation durations were shorter for the words that kept the upper part than for the words that kept the lower part (248 vs. $286 \mathrm{~ms}$, respectively; $p \mathrm{~s}<.001)$. The interaction between the two factors was not significant, $F_{1}(2,46)=2.40, M S E=$ $415.2, p>.10 ; F_{2}(2,236)=2.30, M S E=1,400.7, p>.10$.

Critically, the ANOVAs on gaze durations revealed that the magnitude of the word-frequency effect was modulated by type of text, $F_{1}(2,46)=3.95, M S E=1,248.9, p<.03$; $F_{2}(2,236)=3.43, M S E=7,670.3, p<.035:$ The word

Table 3 Local measures for the different experimental conditions in the experiment (means and standard errors): first-fixation duration, gaze duration, total time, and relative initial landing position

\begin{tabular}{|c|c|c|c|c|c|c|c|c|c|c|c|c|c|c|c|c|}
\hline & \multirow{2}{*}{\multicolumn{4}{|c|}{$\begin{array}{l}\text { First-fixation duration } \\
\text { Word frequency }\end{array}$}} & \multirow{2}{*}{\multicolumn{4}{|c|}{$\frac{\text { Gaze duration }}{\text { Word frequency }}$}} & \multirow{2}{*}{\multicolumn{4}{|c|}{$\frac{\text { Total time }}{\text { Word frequency }}$}} & \multirow{2}{*}{\multicolumn{4}{|c|}{$\begin{array}{l}\text { Landing position } \\
\text { Word frequency }\end{array}$}} \\
\hline & & & & & & & & & & & & & & & & \\
\hline & \multicolumn{2}{|l|}{ low } & \multicolumn{2}{|c|}{ high } & \multicolumn{2}{|l|}{ low } & \multicolumn{2}{|l|}{ high } & \multicolumn{2}{|l|}{ low } & \multicolumn{2}{|c|}{ high } & \multicolumn{2}{|l|}{ low } & \multicolumn{2}{|l|}{ high } \\
\hline & $M$ & $S E$ & $M$ & $S E$ & $M$ & $S E$ & $M$ & $S E$ & $M$ & $S E$ & $M$ & $S E$ & $M$ & $S E$ & $M$ & $S E$ \\
\hline \multicolumn{17}{|l|}{ Type of text } \\
\hline Intact & 238 & 6.2 & 217 & 6.6 & 286 & 7.0 & 244 & 7.1 & 382 & 22.0 & 313 & 14.4 & 0.43 & 0.02 & 0.42 & 0.02 \\
\hline Upper part only & 263 & 7.0 & 232 & 4.9 & 346 & 13.1 & 282 & 10.0 & 454 & 21.3 & 355 & 14.7 & 0.41 & 0.02 & 0.41 & 0.02 \\
\hline Lower part only & 292 & 7.8 & 280 & 6.7 & 504 & 22.9 & 422 & 16.9 & 897 & 51.1 & 714 & 38.8 & 0.38 & 0.01 & 0.42 & 0.01 \\
\hline
\end{tabular}


frequency effect was $42 \mathrm{~ms}$ for the intact words, whereas it was $64 \mathrm{~ms}$ for the words that kept only their upper part and $82 \mathrm{~ms}$ for the words that kept only their lower part, respectively. In addition, the main effects of type of text, $F_{1}(2,46)=59.03, M S E=2,419.2, p<$ $.001 ; F_{2}(2,236)=151.6, M S E=7,670.2, p<.001$, and word frequency, $F_{1}(1,23)=98.15, M S E=52,040$, $p<.001 ; F_{2}(1,118)=45.50, M S E=9,960.3, p<.001$, revealed the same pattern of data as in the first-fixation durations.

The ANOVAs on the total time also revealed that the magnitude of the word frequency effect was modulated by the type of text $(70 \mathrm{~ms}$ for the intact words, $99 \mathrm{~ms}$ for the words that kept only the upper part, and $185 \mathrm{~ms}$ for the words that kept only the lower part), as deduced from the interaction between the two factors, $F_{1}(2,46)=4.43, M S E=$ 9,572.9, $p<.02 ; F_{2}(2,236)=3.22, M S E=50,343.5, p<$ .045. Again, the main effects of type of text, $F_{1}(2,46)=$ $114.2, M S E=26,192.5, p<.001 ; F_{2}(2,236)=151.1, M S E=$ $50,343.5, p<.001$, and word frequency, $F_{1}(1,23)=34.22$, $M S E=14,425.0, p<.001 ; F_{2}(1,118)=19.16, M S E=$ $75,969.6, p<.001$, were significant; the pattern was the same as that with first-fixation durations and gaze durations.

Because target word length varied between six and nine letters, the analysis of the initial landing position was not based on the absolute initial landing position - which goes from 0 until the number of letters of the word-but on the relative initial landing position. This was computed as the absolute initial landing position divided by the number of letters of the target word (see Hohenstein, Laubrock, \& Kliegl, 2010, for a similar procedure). The average initial landing position was slightly to the left of the middle of the word $(M=.41)$. The ANOVA on the initial landing position revealed only a marginal interaction between type of text and word frequency, $F_{1}(2,46)=3.07, M S E=0.003, p=$ $.056 ; F_{2}(2,236)=2.87, M S E=0.007, p=.058$. This reflected the fact that while there were no trends of an effect of type of text for high-frequency words, both $F \mathrm{~s}<1$, type of text modulated the initial landing position for lowfrequency words, $F_{1}(2,46)=3.97, M S E=0.004, p<$ $.027 ; F_{2}(2,118)=5.36, M S E=0.006, p<.007$ : The initial landing position of words that kept only their lower part was slightly closer to the beginning of the word than in the other two conditions (see Table 3).

\section{Discussion}

The present experiment tested the role of the upper versus lower parts of words during normal reading by presenting sentences in which the lower or upper part of the words was removed. As anticipated by Huey (1908), the upper part of the words was much more important during normal reading than was the lower part of the words. When the upper part of the text was removed, participants had more fixations (both progressive and regressive), longer fixation durations (both progressive and regressive), and therefore, longer reading times than when the lower part of the text was removed. The pattern of data when the lower part of the words was removed was somewhat closer to that of the intact sentences: There was some reading cost in the fixation durations and the number of progressive fixations, but not the number of regressive saccades (i.e., an index of reading difficulty), in the analysis by participants.

The sentences in which the upper part of the words was removed showed an important reading cost, as shown in the eye movement data and the comprehension scores. Nonetheless, despite this substantial reading cost, text deterioration did not push landing position to the beginning of the words for high-frequency words, while there was a very small effect for low-frequency words. This dissociation between when and where to move the eyes suggests that these two decisions are (to a large degree) independent, as was claimed by Reichle et al. (1998). More specifically, the decision on where to move the eyes seems to be determined mainly by low-level visual cues (e.g., the location of the word boundaries; Rayner et al., 1998; see also Perea \& Acha, 2009), whereas the decision of when to move the eyes is more closely tied to higher-level processing.

What is the locus of the advantage for the upper part of words during normal reading? As was indicated in the introduction, the lack of an advantage for the upper part of isolated letters and pseudowords strongly suggests that the bias for the upper part of words must have a lexical component. For the general class of models in which there is a "letter-to-word conversion stage" in which lexical knowledge feeds back into letter identification (e.g., the interactive-activation model [McClelland \& Rumelhart, 1981] and its successors), one would expect that word frequency interacts with text degradation-except in early processing of the stimuli, as reflected in first-fixation durations (see Paap et al., 1982, for an activation-verification model). Consistent with this claim, the present experiment revealed that the effect of word frequency was greater for the words that kept only their lower part $(82 \mathrm{~ms})$ than for the words that were presented intact $(42 \mathrm{~ms})$ or the words that kept only their upper part (64 ms); note that gaze duration is a more reliable test of "word difficulty" than is first-fixation duration (Rayner et al., 2012). Thus, there was some cost at the word-identification stage in the degraded conditions - in particular, when the upper part was removed in the less frequent words. Thus, the present data are consistent with the view that the bias for the upper part of (isolated) words has its origin in the interaction between the letter and word levels, rather than merely at the letter level (Perea et al., in press). To examine in finer detail the time course of the bias 
(or lack thereof) for the upper part of letters/words, it will be important to obtain a continuous measure of letter/word processing by recording event-related potentials.

In sum, the present experiment has demonstrated the importance of the upper part of words during normal silent reading, as Huey (1908) had anticipated. Removing the lower part of the words involves some reading cost, but this cost is considerably smaller than when the upper part of the words is deleted. The effect has a lexical nature, as deduced from its absence with isolated letters (see Fiset et al., 2009, Fiset et al., 2008) and its interaction with word frequency. Finally, at an applied level, the present data give partial support to the claims made in "speed reading" courses that assert that the upper part of words enjoys a special status during reading (Wechsler \& Bell, 2005). More research should be conducted to examine whether the bias for the upper part of words is related to a more general bias for the upper part of objects.

Acknowledgments This research has been supported by Grant PSI2011-26924 from the Spanish Ministry of Science and Innovation. I thank Ken Paap and two anonymous reviewers for very helpful comments on a previous version of the manuscript.

\section{References}

Blais, C., Fiset, D., Jolicoeur, P., Arguin, M., Bub, D. N., \& Gosselin, F. (2009). Reading between eye saccades. PLoS One, 4(7), e6448. doi:10.1371/journal.pone. 0006448

Davis, C. J. (2010). The spatial coding model of visual word identification. Psychological Review, 117, 713-758.

Davis, C. J., \& Perea, M. (2005). BuscaPalabras: A program for deriving orthographic and phonological neighborhood statistics and other psycholinguistic indices in Spanish. Behavior Research Methods, 37, 665-671.

Engbert, R., Nuthmann, A., Richter, E., \& Kliegl, R. (2005). SWIFT: A dynamic model of saccade generation during reading. Psychological Review, 112, 777-813.

Fiset, D., Blais, C., Arguin, M., Tadros, K., Éthier-Majcher, C., Bub, D., \& Gosselin, F. (2009). The spatio-temporal dynamics of visual letter recognition. Cognitive Neuropsychology, 26, 23-35.

Fiset, D., Blais, C., Éthier-Majcher, C., Arguin, M., Bub, D., \& Gosselin, F. (2008). Features for identification of uppercase and lowercase letters. Psychological Science, 19, 1161-1168.

Hohenstein, S., Laubrock, J., \& Kliegl, R. (2010). Semantic preview benefit during eye movements in reading: A parafoveal fastpriming study. Journal of Experimental Psychology: Learning, Memory, and Cognition, 36, 1150-1170.

Huey, E. B. (1908). The psychology and pedagogy of reading. New York: McMillan. Republished in 1968. Cambridge: MA: MIT Press.
McClelland, J. L., \& Rumelhart, D. E. (1981). An interactive activation model of context effects in letter perception: Part 1. An account of Basic Findings. Psychological Review, 88, 375-407.

Morin-Duchesne, X., Fiset, D., Arguin, M., \& Gosselin, F. (2012, May). From letter features to syllables to words, without a letter stage. Poster presented at the Vision Sciences Society Annual Meeting, Naples-FL.

Paap, K. R., Newsome, S. L., McDonald, J. E., \& Schvaneveldt, R. W. (1982). An activation-verification model for letter and word recognition. Psychological Review, 89, 573-594.

Paterson, K. B., \& Jordan, T. R. (2010). Effects of increased letter spacing on word identification and eye guidance during reading. Memory \& Cognition, 38, 502-512.

Perea, M., \& Acha, J. (2009). Space information is important for reading. Vision Research, 49, 1994-2000.

Perea, M., Comesaña, M., \& Soares, A. P. (in press). Does the advantage of the upper part of words occur at the lexical level? Memory and Cognition. doi:10.3758/s13421-012-0219-z

Perea, M., Comesaña, M., Soares, A. P., \& Moret-Tatay, C. (2012). On the role of the upper part of words in lexical access: Evidence with masked priming. Quarterly Journal of Experimental Psychology, 65, 911-925.

Perea, M., \& Rosa, E. (2002). Does "whole word shape" play a role in visual word recognition? Perception \& Psychophysics, 64, 785794.

Pollatsek, A., \& Rayner, K. (1982). Eye movement control in reading: The role of word boundaries. Journal of Experimental Psychology. Human Perception and Performance, 8, 817833.

Rayner, K., Fischer, M. H., \& Pollatsek, A. (1998). Unspaced text interferes with both word identification and eye movement control. Vision Research, 38, 1129-1144.

Rayner, K., Liversedge, S. P., White, S. J., \& Vergilino-Perez, D. (2003). Reading disappearing text: Cognitive control of eye movements. Psychological Science, 14, 385-388.

Rayner, K., Pollatsek, A., Ashby, J., \& Clifton, C., Jr. (2012). The Psychology of Reading (2nd ed.). NY: Psychology Press.

Rayner, K., White, S. J., Johnson, R. L., \& Liversedge, S. P. (2006). Raeding wrods with jubmled lettres: There is a cost. Psychological Science, 17, 192-193.

Reichle, E. D., Pollatsek, A., Fisher, D. L., \& Rayner, K. (1998). Toward a model of eye movement control in reading. Psychological Review, 105, 125-157.

Wechsler, H. B., \& Bell, A. (2005). Speed reading for professionals. Hauppauge, NY: Barron's Business Success Guides.

White, S. J., Johnson, R. L., Liversedge, S. P., \& Rayner, K. (2008). Eye movements when reading transposed text: The importance of word beginning letters. Journal of Experimental Psychology. Human Perception and Performance, 34, 1261-1276.

White, S. J., \& Staub, A. (2012). The distribution of fixation durations during reading: Effects of stimulus quality. Journal of Experimental Psychology. Human Perception and Performance, 38, 603617. 